\title{
Chapter 7 \\ Exclusion from Social Relations Among \\ Older People in Rural Britain \\ and Belgium: A Cross-National \\ Exploration Taking a Life-Course \\ and Multilevel Perspective
}

\author{
Sofie Van Regenmortel, Bethan Winter, Angelika Thelin, Vanessa Burholt, \\ and Liesbeth De Donder
}

\subsection{Introduction}

European countries are facing many challenges related to demographic changes and economic conditions. Recent evidence shows increasing socio-economic inequalities which are having a devastating effect on many people's lives (Joseph Rowntree Foundation and Bevan Foundation 2016). Such inequalities are also evident among older adults, with a significant proportion of this population experiencing disadvantage and social exclusion (Walsh et al. 2017). Social exclusion encompasses many forms: exclusion from socio-cultural participation, exclusion from services, exclusion from financial and material resources, exclusion from decent housing, ageism (Van Regenmortel et al. 2016; Walsh et al. 2017) but also exclusion from social relations which is a significant issue for older people within different countries (Winter 2018; Burholt et al. 2019).

As pointed out by Tsakloglou and Papadopoulos (2002) [and in the Introduction to this volume], social exclusion is "relative" implying that social exclusion does not manifest itself in the same way across countries. Not only prevalence, but also

\footnotetext{
S. Van Regenmortel $(\bowtie) \cdot$ L. De Donder

Department of Adult Educational Sciences, Vrije Universiteit Brussel, Brussels, Belgium e-mail: sofie.van.regenmortel@vub.be

B. Winter

Centre for Innovative Ageing, College of Human and Health Sciences, Swansea University, Wales, UK

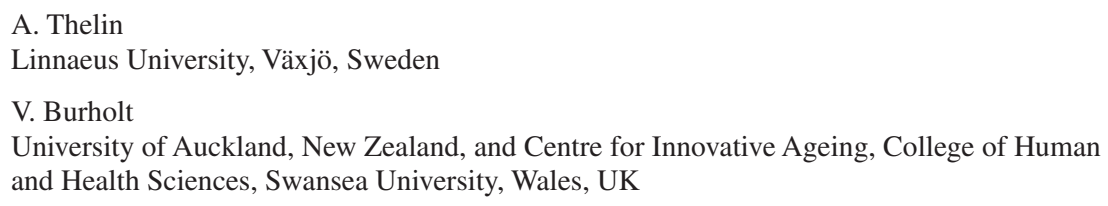


risk factors differ, leading to different national patterns (Pirani 2013). Some studies find, for instance, a higher risk of social exclusion in rural areas (Shergold and Parkhurst 2012; Spoor 2013; Vidovićová et al. this volume), while others find that urban dwelling individuals are at higher risk (Ogg 2005; Barnes et al. 2006; Nicholson and Cooper 2013). However, while a substantial body of literature on the social relations of older people exists, there is a paucity of cross-national comparative research on the topic of exclusion from social relations. This chapter attempts to address this gap by drawing upon two studies, conducted in rural Britain and Belgium, to explore similarities and differences in older people's experience of exclusion from social relations.

The chapter focuses on the following questions:

1. How does exclusion from social relations manifest among older people across rural Britain and Belgium?

2. What are the drivers that contribute to exclusion from social relations for older people within and across these countries?

This chapter will start with a definition of exclusion from social relations, and a summary of the outcomes and drivers of this form of exclusion documented in the international literature. In the following sections, a brief insight is given to the data and methods of the studies. Next, the results are presented: first the quantitative results, then the qualitative insights. Finally, the conclusions are summarised and limitations and paths for policy recommendations and further cross-national research are discussed.

\subsection{Literature Overview}

Drawing on a recent scoping review of social exclusion literature by Walsh et al. (2017), and as outlined by Burholt and Aartsen introducing this section, we conceptualise social relations as comprising social resources, social connections and social networks. This domain of exclusion is partially concerned with the ability of individuals to establish, develop and maintain relationships with family, friends and neighbours. The frequency, closeness and quality of these relationships are important factors to be taken into consideration (Barnes et al. 2006; Lubben 2006; Burholt et al. 2019).

In terms of outcomes, evidence suggests that good and extensive social relations with a range of people and groups including family, friends, neighbours and community groups foster social inclusion (Barnes et al. 2006; Gray 2009). Positive social relations have been found to be a significant source of satisfaction and meaning for older people (Gallagher 2012). Social relations can be a source of advice and support in a variety of ways, including providing care, transport or financial assistance, thus enabling older people to continue their lifestyle and maintain their independence (Scharf and Bartlam 2008). There is also good evidence that good social relations can help older people to maintain physical and psychological health and 
functioning (Gallagher 2012; Courtin and Knapp 2017; Shankar et al. 2017). Conversely, exclusion from social relations has been associated with greater levels of loneliness in the older population (de Jong Gierveld et al. 2006; Victor et al. 2008). Exclusion from social relations can lead to reduced social opportunities such as employment, volunteering, or other forms of social participation (Phillipson et al. 2004; de Espanés et al. 2015).

When looking at the drivers of social exclusion, we adopt a critical human ecological theoretical framework (Keating and Phillips 2008) and draw on three "systems" or levels within the ecological model to contextualise our approach. These are (i) the macro system which incorporates structural issues including ideology, political landscape, norms, values, and national policies; (ii) the exosystem which refers to structure and organisations that affect the immediate environment - that is, natural and physical elements of the environment, alongside services, amenities and employment opportunities in the local area; (iii) the microsystem which focuses upon individual characteristics, traits and attributes (Burholt et al. 2019). In addition to these three systems, the mesosystem comprises interactions between microsystems. While this is not explicitly labelled in this chapter, the interactions and interconnections between systems are referred to in each section.

At a macro level, cultural and policy effects exclusion from social relations. Normative expectations about sources of support and family forms have a bearing on the extent to which social relations can protect or buffer an older person from adverse outcomes. In more individualistic cultures, the state or the market are recognised as important actors in providing welfare for older persons in need. In more collectivistic cultures, private social networks and the civic sector are emphasised as important actors on this matter. The normative configuration of networks of family and friends differs between individualist and collectivist cultures and deviations from normative networks result in greater loneliness for older people (Burholt and Dobbs 2014; Winter 2018). Also (stereotypical) attitudes and beliefs towards older people and the ageing process (e.g. ageism), influence older adults' inclusion in social networks (Burholt et al. 2019).

In the exosystem the physical environment has an important influence on exclusion from social relations. For example, neighbourhood design, housing diversity, population density, mixed land use and open space are associated with walkability and social contact (Bowling and Stafford 2007; Byles et al. 2014; Lager et al. 2015; Burholt et al. 2016). The influence of the environment on social relations could be also considered in terms of settlement type, which may be defined using clusters of variables describing different types of rural/urban areas, or areas experiencing multiple deprivations or disadvantages [see Drilling et al. and Vidovićová et al. this volume]. While some authors have noted that exclusion from social relations is particularly pronounced for those living in deprived and remote rural areas (Milne et al. 2007), Scharf et al. (2005) found that older people living in deprived urban areas are more vulnerable to exclusion from social relations than those living in the UK as a whole. A close association has also been found between community change, notably inward-outward migration, population change and exclusion from social resources (Scharf and Bartlam 2008; Gray 2009). Population change for example 
may have a detrimental impact upon social relations of the indigenous local older people whose family networks may no longer be available, as well as on the networks of older people that have moved into an area and who do not have access to local support that has been established over time (Scharf and Bartlam 2008; Burholt and Sardani 2017).

At a micro level, studies reveal that certain individual characteristics or life events impact on exclusion from social relations including gender, marital status, health, retirement and socio-economic status [see Urbaniak et al. this volume]. While social isolation is more common for women than men (Wenger et al. 1996), the differences are largely due to differences in marital status with women more likely to be widowed and living alone. Older people who are living alone and those without children are most likely to experience difficulties with regards to social resources (Gray 2009). Poor health is also a risk for exclusion from social relations: poor health, impairment or pain impact on the ability to maintain usual lifestyles including customary levels of social interaction and can precipitate a decline in social relations (Bertoni et al. 2015; Hilaria and Northcott 2017). Research across a range of countries, reveals that material deprivation and poverty limits full participation in the social life of communities for older people, limiting opportunities to optimise and diversify social interaction, and contribute significantly to exclusion from social relations (Ajrouch et al. 2005; Ellwardt et al. 2014; see Sumil-Laanemaa et al. and Barlin et al. this volume).

\subsection{Data and Methods}

\subsubsection{General Research Approach}

To answer the research questions, the chapter draws upon two $\mathrm{PhD}$ studies on rural Britain (Winter 2018) and Belgium (Van Regenmortel 2017). Both studies show some similarities and differences. In terms of similarities, both used a theoretical framework informed by the life-course and exclusion literature. Both also examined social exclusion in general, with exclusion from social relations emerging as an important domain in their studies. Finally, both studies used a similar mixed method design: quantitative analyses of survey data and qualitative life story interviews. In terms of differences, the research in rural Britain was conducted between 2012 and 2017, and studied older people's experience of social exclusion underpinned by a transformative worldview (Winter 2018). The Belgian study of Van Regenmortel (2017) conducted between 2013 and 2017 was built upon a lifecourse perspective and environmental gerontology to study old-age social exclusion. In addition, the British study focused on rural-dwelling older adults in England and Wales, while the Belgian study included both rural and urban communities in the research. 


\subsubsection{Quantitative Phase}

The quantitative phase of both cross-sectional studies examined the different categories of social exclusion through secondary analysis of existing datasets within each country: Grey and Pleasant Land study (2014) conducted in rural Britain (South West England and Wales) (Hennessy et al. 2014a); Belgian Ageing Studies (data collected in different municipalities between 2008 and 2014) in Belgium. In both studies, exploratory latent class analysis was used to develop classes of social exclusion that best fitted the data for older people living in rural Britain and Belgium.

The Belgian study operationalised social exclusion based on a systematic review conducted earlier (Van Regenmortel et al. 2016) and the data available in the large-scale quantitative Belgian Ageing Studies survey. This resulted in four sub dimensions for exclusion from social relations (for more detailed information on data collection and analysis, see Van Regenmortel et al. 2017). In the rural Britain study the best fit model used all relevant available data (for more detailed information on data collection and analysis, see Hennessy et al. 2014b). Table 7.1 shows how exclusion from social relations was operationalised in both quantitative studies.

Table 7.1 Operationalisation of exclusion from social relations in the rural Britain and Belgian studies

\begin{tabular}{|c|c|}
\hline \multicolumn{2}{|c|}{ Exclusion from social relations } \\
\hline \multicolumn{2}{|c|}{ Rural Britain } \\
\hline $\begin{array}{l}\text { Very lonely } \\
\text { (emotionally \& } \\
\text { socially) }\end{array}$ & $\begin{array}{l}\text { Loneliness was measured using the six-item de Jong Gierveld scale (de Jong } \\
\text { Gierveld and Van Tilburg 2006) which measures loneliness through six } \\
\text { indirect questions about emotional and social loneliness. The total loneliness } \\
\text { score was the sum of the two scores (emotional \& social) with scores ranging } \\
\text { from zero (not lonely) through to six (extremely lonely) (de Jong Gierveld } \\
\text { and Van Tilburg 1999). }\end{array}$ \\
\hline $\begin{array}{l}\text { Exclusion from } \\
\text { social ties }\end{array}$ & $\begin{array}{l}\text { An amended version of the Lubben Social Network Scale (LSNS-6) was used } \\
\text { to measure exclusion from social relations. The scale consists of three } \\
\text { questions that calculate kinship ties and three questions that assess non-kin } \\
\text { ties. Lower scores indicated fewer social relations and higher scores indicated } \\
\text { more social relations. }\end{array}$ \\
\hline \multicolumn{2}{|l|}{ Belgium } \\
\hline $\begin{array}{l}\text { Very } \\
\text { emotionally } \\
\text { lonely }\end{array}$ & $\begin{array}{l}\text { Loneliness was measured using the six-item de Jong Gierveld scale (de Jong } \\
\text { Gierveld and Van Tilburg 2006). If respondents indicated for each of the three } \\
\text { emotional loneliness indicators that they were lonely, they were assessed as } \\
\text { very emotionally lonely. }\end{array}$ \\
\hline $\begin{array}{l}\text { Very socially } \\
\text { lonely }\end{array}$ & $\begin{array}{l}\text { Derived from the six item scale for loneliness (de Jong Gierveld and Van } \\
\text { Tilburg 2006). If respondents indicated for each of the three social loneliness } \\
\text { variables that they were lonely, they were assessed as very socially lonely. }\end{array}$ \\
\hline $\begin{array}{l}\text { Exclusion from } \\
\text { social contacts }\end{array}$ & $\begin{array}{l}\text { If respondents did not have at least once-a-month contact with family } \\
\text { members, friends or neighbours they were considered as excluded from social } \\
\text { contacts. }\end{array}$ \\
\hline $\begin{array}{l}\text { Exclusion from } \\
\text { social support }\end{array}$ & $\begin{array}{l}\text { If respondents could not count on support of family members, friends or } \\
\text { neighbours they were considered as excluded from social support. }\end{array}$ \\
\hline
\end{tabular}


These measures that captured exclusion form social relations were taken together with a range of other social exclusion domains (e.g. exclusion from services, exclusion from participation) and latent class analysis was used to develop a model of social exclusion that "best fits" the sample of older people in each of the studies.

\subsubsection{Qualitative Phase}

The qualitative phase of both studies involved life history interviews with older people. In the rural Britain study, the sample was drawn only from Wales for the PhD study: ten older people in three rural case study areas $(\mathrm{N}=30)$ were recruited, using purposive sampling, for life history interviews (Winter and Burholt 2018). Interviews focussed upon hardship and prosperity. An Interpretive Phenomenological Analytical approach (IPA) was used to analyse the data. This approach focuses upon understanding participants' subjective realities through personal interpretations of their lived experiences and the meanings they attach to experiences within a specific context (Smith 2004).

Qualitative data in the Belgian PhD study came from 19 life stories of older adults (60+ years) living on low income (for more detailed information on data collection and analysis, see Van Regenmortel et al. 2019). The qualitative study aimed to understand the experience and the narrated life course of financially excluded older adults, and consequently to give voice to groups of people that are often not reached by (longitudinal) surveys (Chamberlayne et al. 2000). The methodology leaned on narrative theory (Bluck and Habermas 2001) and used adapted life story interview guidelines of McAdams $(2005,2008)$ to conduct the study.

\subsection{Results}

The results section first presents the results of the quantitative phase, and then explores the qualitative material.

\subsubsection{Quantitative Results: Manifestations of Exclusion from Social Relations Among Older People Across Rural Britain and Belgium}

Table 7.2 provides the results from the Latent Class Analyses on the nature and level of social exclusion experienced by older people in rural Britain and Belgium. 
Table 7.2 Categories of old-age social exclusion after latent class analysis

\begin{tabular}{|c|c|}
\hline Rural Britain ( $\mathrm{N}=864$ rural $)$ & Belgium $(\mathrm{N}=20,275$ rural $\&$ urban $)$ \\
\hline $\begin{array}{l}\text { Least Social Exclusion ( } 76 \%) \text { : high levels } \\
\text { of social relations, lowest levels of poverty, } \\
\text { least difficulty accessing services and } \\
\text { accessing leisure and cultural amenities, } \\
\text { broadest civic engagement and participation }\end{array}$ & $\begin{array}{l}\text { Low Risk of Social Exclusion ( } 45.7 \%) \text { : high } \\
\text { levels of social relations, low risk of exclusion } \\
\text { from civic participation, financial resources, the } \\
\text { neighbourhood, decent housing and services, low } \\
\text { level of digital exclusion and ageism. }\end{array}$ \\
\hline
\end{tabular}

\begin{abstract}
Moderate Social Exclusion (13\%): high levels of social relations, moderate to low difficulty accessing services, leisure and cultural amenities, broad civic engagement and participation in individual activities, higher levels of poverty.
\end{abstract}

\section{Moderate Social Exclusion but Service} Poor (7\%): high level of social relations, broad participation in individual activities and moderate civic engagement, moderate to high difficulty accessing services, leisure and cultural amenities and higher levels of poverty.

\section{Extreme Social Exclusion (4\%): lowest level of social relations, greatest difficulty accessing services, leisure and cultural amenities, low civic engagement and participation in individual activities, higher levels of poverty.}

\section{Non- participating Financially Excluded}

(25.5\%): high digital exclusion, high levels of exclusion from civic participation and financial exclusion / higher levels of social relations, inclusion in the neighbourhood, high levels of access to decent housing, services and less ageism.

Environmentally Excluded (12.5\%): exclusion from social relations, services, neighbourhood, decent housing and ageism.

Severely Excluded (16.2\%): a higher probability of combined exclusion in all dimensions of old-age social exclusion.

Analysis of the rural British data identified four latent classes. First, people classified in the "Least Social Exclusion" class were the largest group. They had high levels of social relations and the lowest levels of poverty. These older people had the least difficulty accessing services and accessing leisure and cultural amenities. They had the broadest involvement in civic engagement and the broadest participation in individual activities. Second, the "Moderate Social Exclusion" class was the second largest class. People classified in this group had high levels of social relations, moderate to low difficulty accessing services and moderate difficulty accessing leisure and cultural amenities. People in this class had broad involvement in civic engagement and broad participation in individual activities. They also had relatively high levels of poverty. Third, people in the "Moderate Social Exclusion but Service Poor" class had a high level of social relations, broad participation in individual activities and moderate involvement in civic engagement. However, they had moderate to high difficulty accessing services and moderate difficulty accessing leisure and cultural amenities. They also experienced relatively high levels of poverty. Fourth, people classified in the "Extreme Social Exclusion" group experienced the lowest level of social relations, the greatest difficulty accessing services and the greatest difficulty accessing leisure and cultural amenities [see Gallistl this volume for an exploration of the links between cultural participation and socio-economic 
status]. They had low involvement in civic engagement and low participation in individual activities. These people had relatively high levels of poverty.

The Belgian study also generated four different classes. The first class "Low Risk of Social Exclusion" had high levels of social relations and the lowest risk to be excluded from civic participation, financial resources, the neighbourhood, and decent housing. This category also had the lowest level of digital exclusion experiences or feelings of ageism. They had a considerably low chance of being excluded from services. Second, "Non- participating Financially Excluded" were older adults that combined the highest chance of digital exclusion [see Poli et al. this volume] with higher levels of exclusion from civic participation together with financial exclusion. They had, however, higher levels of social relations, and lower levels of exclusion from the neighbourhood, decent housing, and services and they experienced less ageism. Third, the "Environmentally Excluded" category were the most likely to have experienced exclusion from social relations and services. Furthermore, they experienced a higher probability of neighbourhood and housing exclusion. They also had a higher probability of feeling excluded due to their age (ageism). Fourth, the "Severely Excluded" experienced, compared to the total population, a higher probability of combined exclusion in all dimensions of old-age social exclusion.

It was striking how similar the characteristics of the latent classes were across both studies. One difference could be found in terms of social relations: in the rural Britain study exclusion from social relations was confined to one class which consisted of a small minority of the sample with only $4 \%$ comprising the "Extreme Social Exclusion" class. In contrast, exclusion from social relations affected a much larger proportion of older people in the Belgium study across two classes, namely the "Environmentally Excluded" (12.5\%) and the "Severely Excluded" (16.2\%). This may be because exclusion from social relations was operationalised differently in both studies, or because the areas selected (rural vs rural plus urban) experienced different levels of exclusion from social relations.

\subsubsection{Qualitative Results: Manifestations and Drivers of Exclusion from Social Relations throughout the Life Course}

First the results of the life story interviews in rural Britain are discussed. This is followed by the results of the life stories in Belgium. For both studies, manifestations of exclusion from social relations, and then the drivers of exclusion (in the microsystem, exosystem and macrosystem) will be discussed. 


\subsubsection{Rural Britain Study}

In rural Britain (Wales only) the qualitative evidence suggested that relationships with family, friends and neighbours were a source of inclusion for the majority of participants during their childhood and working adult lives. For example, one male participant commented that:

'So, as I say it was a good place to be brought up in because you knew all your neighbours, friends and their parents as well.' (M 86 years)

These social relations were vital for several reasons. First, they were a source of emotional and instrumental support for participants and fostered a positive sense of community. Second, a number of participants linked their close family relationships to their limited material resources, explaining that living with extended family was a necessity because of poverty. This was especially true in the pre-Second World War period when state assistance was minimal. Some participants described how their family would care for family members suffering ill health, sometimes resulting in co-residence. Third, local people often worked and socialised together. Networks were important in terms of security and safety and created a sense of a close-knit community.

\footnotetext{
'You were in it together and no household was different to the other. It didn't matter about your status, your income or anything like... because people lived in the valley and they stayed in the valleys. They didn't move out.' (M, 95 years)
}

In rural Britain, exclusion from social relations was a problem for a small minority of participants during childhood and early adulthood. This was attributable to the remoteness of their homes: they lived either on farms or small holdings located a significant distance from others (family, friends and neighbours) as well as from services and activities. These participants explained that the experience of exclusion from social relations caused feelings of isolation and loneliness, especially during their childhood when they yearned to have friends to play with, as evidenced by the following quote from one participant:

'[I was] a very remote and lonely child really, because I didn't have anyone to play with. I would play with the cats mostly [...] and I had my dolls. But there were no children for me to play with.' (F 81 years)

Exclusion from relationships with family and neighbours became an increasing concern as participants aged, resulting in feelings of loneliness and isolation. This was the result of primary drivers of exclusion from social relations: older age (microsystem), bereavement (microsystem), remote and rural living (exosystem) and population change (macrosystem).

Bereavement had a significant impact on social relations for some participants resulting in feelings of loneliness and isolation. For example, one participant spoke at length about the effect that the death of his wife four years earlier from a short illness had on his life. He recollected that they were married for over 50 years and were extremely close, doing everything together and being a source of support to 
one another. He explained that currently, with his two sons living away and few friends in the locality, his social relations were dwindling.

Participants felt that population turnover had a negative impact on community cohesion and their sense of belonging. Out-migration was impacting negatively upon older people's social relations, in particular on the availability of family to provide physical and emotional support. For example, one participant who lived alone and whose son lived and worked abroad, expressed frustration at not having family nearby to ask for help with such tasks as household repairs. She also expressed deep sadness at the loss of emotional support and, during the interview, alluded to feeling lonely. At the same time in-migration had a negative impact on social relations of participants, especially neighbours. While a few participants spoke positively about their neighbours the majority were critical of those who had migrated to the area who, they felt, were not a source of support and did not contribute to the community. This is illustrated by the following quote:

'Um, I came to know everyone in the village and I could tell which house they were in.

Everyone, I knew everyone, right? But now I don't know those that live on this road here.

That's the difference. People have moved in you see. Strangers and they don't [help]....... the village has completely changed.' (F 81 years)

\subsubsection{Belgian Study}

In Belgium, social relations were an important element in the life stories of financially excluded older adults: both new social relations (e.g. childbirth, marriage) as well as exclusion from social relations (e.g. divorce and death of relatives and friends) were present. This shows the value that is given to social relations in one's life and how previous events and situations impacted on current experiences. When talking about their future lives social relations were emphasised as especially important. Many respondents wanted to live long enough to see (great) grandchildren growing up. Besides maintaining social relations, they also wanted to build new social relations in the future.

'I hope I may be around for many years. For my daughter. And for my grandchildren too.

That I can be here for a long time.' (Leonie, F, 64 years)

Older respondents experienced exclusion because of social relations. Social relations were then drivers of old-age social exclusion. Marie, for instance, (F, 73 years) considered the bad way her mother treated her to be a major influence throughout her life, because it created an inferiority complex. Other respondents spoke about being scammed by their acquaintances or business partners, leading to financial difficulties and even bankruptcy. Taking custody of grandchildren had also led to financial difficulties and a significant decrease in participation in social and civic activities [see Waldegrave et al. this section for an in-depth discussion of conflicting social relations]. 
The older people interviewed did, however, not only problematise social relations but viewed them as a significant enabler for the future. This was especially the case if people had bad health or a disability. In many life stories, having (quality) social relations and social support could prevent (further) exclusion in different fields. For instance, Jos, an 81-year-old man, recounted that after a life full of misery and worries, the help of his wife was indispensable. Thanks to her, he went to the public service for local welfare and received help. For some older adults, the support of relatives mitigated financial or material difficulties slightly. This was illustrated by this account of Jos, whose son bought him a car.

'I drove fifteen years with that car. At the end, the car was worn out and I had no car anymore. My son said that I should have a car. We were in the garage and there was a little second-hand car for 2500 euros. My son bought me the car.' (Jos, M, 81 years)

Older respondents experienced exclusion because of the cumulative effects of particular drivers on the development of social relations over time. Important drivers were: divorce/widowhood (micro), financial difficulties (micro), regulations on social benefits (macro).

Divorce and widowhood were often significant life events or turning points causing exclusion from social relations [also see Barlin et al. this volume]. These events led to loneliness and influenced other dimensions of old-age social exclusion (e.g. financial loss).

Having a low income was clearly a driver of exclusion from social relations. Respondents talked about living on a low income and how this caused difficulties in their everyday lives, such as participating less in certain social and cultural activities. Both Roger's (M, 64 years) and Jos's (M, 81 years) social network for instance shrank after going bankrupt and subsequently facing financial difficulties.

A macro-level influence on social relations was the way in which financial social support provided by the government was organised. Some respondents receiving social benefits and having a relationship with someone with social benefits were prohibited to live in the same house, as this would mean a considerable loss for the financial support received.

It was clear from the life stories that there was a relationship between different drivers and the accumulation of turning points. For example, one male participant explained:

'That [depression] all started with my divorce, followed by losing my job and [then there were] all those bereavements. Everything piling up in one year.' (Jef, M, 76 years)

\subsection{Conclusion}

This chapter draws upon two studies conducted in rural Britain and Belgium which explored similarities and differences in older people's experience of exclusion from social relations. Although the research has demonstrated that in both rural Britain and Belgium social relations are vital for several reasons (e.g. health and care, 
practical support in times of poverty, safety), some older participants in both countries face exclusion from social relations (e.g. feelings of loneliness, isolation, 'bad' social relations). In both quantitative studies, exclusion from social relations were manifest in at least one type of old-age social exclusion. In Belgium, exclusion from social relations was more broadly operationalised which led to larger old-age social exclusion classes.

A second similarity between the studies is the strong interrelationship between exclusion from social relations with other domains of exclusion (e.g. economic and material exclusion). These interrelationships were also clearly demonstrated in the life story interviews (e.g. exclusion from social relations as a driver for other types of exclusion and vice versa).

In terms of drivers of exclusion from social relations the life stories revealed micro (e.g. marital status, gender), exo (e.g. being remote and rural living) and macro drivers of exclusion from social relations (e.g. the way in which financial social support provided by the government was organised, and population change).

Some limitations of the current research should be highlighted. Although the quantitative and qualitative research methods of both studies are very similar, differences posed challenges to this cross-national exploration. Not only do Britain and Belgium differ in language and socio-political organisation, but the way in which data were sampled and collected was not identical. These challenges should be taken into account when interpreting this cross-national exploration. The contribution of this chapter lays in the bringing together of existing quantitative and qualitative data sources for a cross-national explorative purpose in order to understand exclusion from social relations, and old-age social exclusion in general. Further cross-national explorative comparative research on the subject and with a common methodological approach is needed. We hope that such further research will find inspiration from the results of this and other already conducted explorative crossnational studies.

Based on our findings, two main recommendations can be identified. First, a multilevel approach targeting exo and macro factors is needed as not only individual factors (e.g. gender, age, education) influence the likelihood of being excluded from social relations. The fact that older adults tend to age in place (Wagner et al. 2010) and that they rely on resources and services available in the locality because of their reduced action radius (Krause 2004), promotes a focus on investing in the creation of age-friendly and prosperous environments to enable social inclusion (Scharlach et al. 2013; Drilling et al. this volume). Second, the life story interviews in both studies show that life events [see also Urbaniak et al. this volume] might influence exclusion from social relations in both the short and long-term. Consequently, policy tackling old-age social exclusion might usefully approach this form of exclusion from a life-course perspective, which means that fighting old-age social exclusion already starts with preventing and fighting exclusion at earlier life stages (Scharf et al. 2005). From this study, and earlier research, it is clear that disadvantages in different life stages are connected and therefore a life-course oriented social policy is needed. 


\section{Editors' Postscript}

Please note, like other contributions to this book, this chapter was written before the COVID-19 pandemic of 2020. The book's introductory chapter (Chap. 1) and conclusion (Chap. 34) consider some of the key ways in which the pandemic relates to issues concerning social exclusion and ageing.

\section{References}

Ajrouch, K. J., Blandon, A. Y., \& Antonucci, T. C. (2005). Social networks among men and women: The effects of age and socioeconomic status. The Journals of Gerontology Series B: Psychological Sciences and Social Sciences, 60(6), S311-S317.

Barnes, M., Blom, A., Cox, K., \& Lessof, C. (2006). The social exclusion of older people: Evidence from the first wave of the English longitudinal study of ageing (ELSA). London: Office of the Deputy Prime Minister, Social Exclusion Unit.

Bertoni, M., Celidoni, M., \& Weber, G. (2015). Does hearing impairment lead to social exclusion? In A. Börsch-Supan, T. Kneip, H. Litwin, M. Myck, \& G. Weber (Eds.), Ageing in Europe Supporting policies for an inclusive society (pp. 93-102). DeGruyter.

Bluck, S., \& Habermas, T. (2001). Extending the study of autobiographical memory: Thinking back about life across the life span. Review of General Psychology, 5(2), 135-147.

Bowling, A., \& Stafford, M. (2007). How do objective and subjective assessments of neighbourhood influence social and physical functioning in older age? Findings from a British survey of ageing. Social Science \& Medicine, 64(12), 2533-2549. https://doi.org/10.1016/j. socscimed.2007.03.009.

Burholt, V., \& Dobbs, C. (2014). A support network typology for application in older populations with a preponderance of multigenerational households. Ageing and Society, 34(7), 1142-1169. https://doi.org/10.1017/S0144686X12001511.

Burholt, V., \& Sardani, A. V. (2017). The impact of residential immobility and population turnover on the support networks of older people living in rural areas: Evidence from CFAS Wales. Population, Space and Place, 24, e2132.

Burholt, V., Roberts, M. S., \& Musselwhite, C. B. A. (2016). Older People's External Residential Assessment Tool (OPERAT): A complementary participatory and metric approach to the development of an observational environmental measure. BMC Public Health, 16(1), 1022. https:// doi.org/10.1186/s12889-016-3681-x.

Burholt, V., Winter, B., Aartsen, M., Constantinou, C., Dahlberg, L., Feliciano, V., et al. (2019). 156 A critical review and development of a conceptual model of exclusion from social relations for older people. European Journal of Ageing, 17, 3-19. https://doi.org/10.1007/ s10433-019-00506-0.

Byles, J. E., Leigh, L., Vo, K., Forder, P., \& Curryer, C. (2014). Life space and mental health: A study of older community-dwelling persons in Australia. Aging and Mental Health, 19(2), 98-106. https://doi.org/10.1080/13607863.2014.917607.

Chamberlayne, P., Bornat, J., \& Wengraf, T. (2000). The turn to biographical methods in social science: Comparative issues and examples. London/New York: Routledge.

Courtin, E., \& Knapp, M., (2017). Social isolation, loneliness and health in old age: A scoping review. Health and Social Care in the Community, 25, 799-812.

de Espanés, G. M., Villar, F., Urrutia, A., \& Serrat, R. (2015). Motivation and commitment to volunteering in a sample of Argentinian adults: What is the role of generativity? Educational Gerontology, 41(2), 149-161.

de Jong Gierveld, J., \& Van Tilburg, T. (1999). Manual of the loneliness scale. Amsterdam: Department of Social Research Methodology, Vrije Universiteit Amsterdam.

de Jong Gierveld, J., \& Van Tilburg, T. (2006). A 6-item scale for overall, emotional, and social loneliness confirmatory tests on survey data. Research on Aging, 28(5), 582-598. 
de Jong Gierveld, J., van Tilburg, T. G., \& Dykstra, P. A. (2006). Loneliness and social isolation. In A. L. Vangelisti \& D. Perlman (Eds.), The Cambridge handbook of personal relationships (pp. 485-500). Cambridge/New York: Cambridge University Press.

Ellwardt, L., Peter, S., Präg, P., \& Steverink, N. (2014). Social contacts of older people in 27 European countries: The role of welfare spending and economic inequality. European Sociological Review, 30(4), 413-430. https://doi.org/10.1093/esr/jcu046.

Gallagher, C. (2012). Connectedness in the lives of older people in Ireland: A study of the communal participation of older people in two geographic localities. Irish Journal of Sociology, 20(1), 84-102. https://doi.org/10.7227/IJS.20.1.5.

Gray, A. (2009). The social capital of older people. Ageing and Society, 29(1), 5-31. https://doi. org/10.1017/S0144686X08007617.

Hennessy, C., Means, R., \& Burholt, V. (2014a). Countryside connections: Older people, community and place in rural Britain. Bristol: Policy Press.

Hennessy, C., Means, R., \& Burholt, V. (2014b). Countryside connections in later life: Setting the scene. In C. Hennessy, R. Means, \& V. Burholt (Eds.), Countryside connections: Older people, community and place in rural Britain (pp. 1-30). Bristol: Policy Press.

Hilaria, K., \& Northcott, S. (2017). "Struggling to stay connected": Comparing the social relationships of healthy older people and people with stroke and aphasia. Aphasiology, 31(6), 647-687. https://doi.org/10.1080/02687038.2016.1218436.

Joseph Rowntree Foundation, \& Bevan Foundation. (2016). Prosperity without poverty: A framework for action in Wales. York: Joseph Rowntree Foundation.

Keating, N., \& Phillips, J. (2008). A critical human ecology perspective on rural ageing. In N. Keating (Ed.), Rural ageing: A good place to grow old (pp. 1-10). Bristol: Policy Press.

Krause, N. (2004). Neighbourhoods, health and wellbeing in later life. In H. W. Wahl et al. (Eds.), Annual review of gerontology and geriatrics (pp. 22-49). New York: Springer.

Lager, D., Hover, B. v., \& Huigen, P. P. (2015). Understanding older adults' social capital in place: Obstacles to and opportunities for social contacts in the neighbourhood. Geoforum, 59, 87-97. https://doi.org/10.1016/j.geoforum.2014.12.009.

Lubben, J. (2006). Abbreviated and targeted geriatric assessment. In B. Berkman (Ed.), Handbook of social work in health and aging (pp. 729-735). New York: Oxford University Press.

McAdams, D. P. (2005). Studying lives in time: A narrative approach. Advances in Life Course Research, 10, 237-258.

McAdams, D. P. (2008). The life story interview. http://www.sesp.northwestern.edu/foley/instruments/interview/. Accessed 15 Sep 2015.

Milne, A., Hatzidimitriadou, E., \& Wiseman, J. (2007). Health and quality of life among older people in rural England: Exploring the impact and efficacy of policy. Journal of Social Policy, $36,477-495$.

Nicholson, L., \& Cooper, S. A. (2013). Social exclusion and people with intellectual disabilities: A rural-urban comparison. Journal of Intellectual Disability Research, 57(4), 333-346. https:// doi.org/10.1111/j.1365-2788.2012.01540.x.

Ogg, J. (2005). Social exclusion and insecurity among older Europeans: The influence of welfare regimes. Ageing \& Society, 25(1), 69-90. https://doi.org/10.1017/S0144686X04002788.

Phillipson, C., Allan, G., \& Morgan, D. (2004). Introduction. In C. Phillipson, G. Allan, \& D. Morgan (Eds.), Social networks and social exclusion: Sociological and policy perspectives (pp. 1-6). Abingdon: Routledge.

Pirani, E. (2013). Evaluating contemporary social exclusion in Europe: A hierarchical latent class approach. Quality \& Quantity, 47(2), 923-941.

Scharf, T., \& Bartlam, B. (2008). Ageing and social exclusion in rural communities. In N. Keating (Ed.), Rural ageing: A good place to grow old? (pp. 97-108). Bristol: Policy Press.

Scharf, T., Phillipson, C., \& Smith, A. E. (2005). Multiple exclusion and quality of life amongst excluded older people in disadvantaged neighbourhoods. London: Social Exclusion Unit.

Scharlach, A. E., Lehning, A. J., Warburton, J., Ng, S. H., \& Shardlow, S. M. (2013). Ageingfriendly communities and social inclusion in the United States of America. Ageing \& Society, $33(1), 110-136$. 
Shankar, A., McMunn, A., Demakakos, P., Hamer, M., \& Steptoe, A. (2017). Social isolation and loneliness: Prospective associations with functional status in older adults. Health Psychology, 36(2), 179.

Shergold, I., \& Parkhurst, G. (2012). Transport-related social exclusion amongst older people in rural Southwest England and Wales. Journal of Rural Studies, 28(4), 412-421. https://doi. org/10.1016/j.jrurstud.2012.01.010.

Smith, J. A. (2004). Reflecting on the development of interpretative phenomenological analysis and its contribution to qualitative research in psychology. Qualitative Research in Psychology, 1(1), 39-54.

Spoor, M. (2013). Multidimensional social exclusion and the 'rural-urban divide' in Eastern Europe and Central Asia. Sociologia Ruralis, 53(2), 139-157. https://doi.org/10.1111/soru.12008.

Tsakloglou, P., \& Papadopoulos, F. (2002). Aggregate level and determining factors of social exclusion in twelve European countries. Journal of European Social Policy, 12(3), 211-225.

Van Regenmortel, S. (2017). Social exclusion in later life: Measurement and drivers of social exclusion among older people (Phd-dissertation). Zelzate: Open University Press.

Van Regenmortel, S., De Donder, L., Dury, S., Smetcoren, A.-S., De Witte, N., \& Verté, D. (2016). Social exclusion in later life: A systematic review of the literature. Journal of Population Ageing, 9, 315-344. https://doi.org/10.1007/s12062-016-9145-3.

Van Regenmortel, S., De Donder, L., Smetcoren, A.-S., Lambotte, D., De Witte, N., \& Verté, D. (2017). Accumulation of disadvantages: Prevalence and categories of old-age social exclusion in Belgium. Social Indicators Research. https://doi.org/10.1007/s11205-017-1817-8.

Van Regenmortel, S., Smetcoren, A., Marsillas, S., Lambotte, D., Fret, B., \& De Donder, L. (2019). Exploring underexposed stories: The experienced lifecourse of financially excluded older adults. Ageing and Society, 1-22. https://doi.org/10.1017/S0144686X19001235.

Victor, C., Scambler, S., \& Bond, J. (2008). The social world of older people: Understanding loneliness and social isolation in later life. London: McGraw-Hill Education.

Wagner, S. L., Shubair, M. M., \& Michalos, A. C. (2010). Surveying older adults' opinions on housing: Recommendations for policy. Social Indicators Research, 99(3), 405-412.

Walsh, K., Scharf, T., \& Keating, N. (2017). Social exclusion of older persons: A scoping review and conceptual framework. European Journal of Ageing, 14(1), 81-98.

Wenger, G. C., Davies, R., Shahtahmasebi, S., \& Scott, A. (1996). Social isolation and loneliness in old age: Review and model refinement. Ageing and Society, 16(03), 333-358. https://doi. org/10.1017/s0144686x00003457.

Winter, B., 2018. Disadvantage and advantage among older people in rural communities in Wales: A multi-level and life-course perspective. $\mathrm{PhD}$. Swansea University, Wales, UK.

Winter, B., \& Burholt, V. (2018). Y Cymry Cymreig: Cultural exclusion among rural-dwelling older people, a critical human ecological approach. International Journal of Aging and Later Life, 12 (2), 119-151. https://doi.org/10.3384/ijal.1652-8670.18399. 
Open Access This chapter is licensed under the terms of the Creative Commons Attribution 4.0 International License (http://creativecommons.org/licenses/by/4.0/), which permits use, sharing, adaptation, distribution and reproduction in any medium or format, as long as you give appropriate credit to the original author(s) and the source, provide a link to the Creative Commons license and indicate if changes were made.

The images or other third party material in this chapter are included in the chapter's Creative Commons license, unless indicated otherwise in a credit line to the material. If material is not included in the chapter's Creative Commons license and your intended use is not permitted by statutory regulation or exceeds the permitted use, you will need to obtain permission directly from the copyright holder. 